\title{
Pre-Treatment of Waste Frying Oils for Biodiesel Production
}

\author{
Nyoman Puspa Asri ${ }^{1}$, Diah Agustina Puspita Sari ${ }^{2}$, Bambang Poedjojono ${ }^{1} \&$ Suprapto $^{3}$ \\ ${ }^{1}$ Department of Chemical Engineering, W R. Supratman University, Indonesia \\ ${ }^{2}$ Chemical Engineering Department, Faculty of Engineering, University of Brawijaya, Indonesia \\ ${ }^{3}$ Chemical Engineering Department, Industrial Technology Faculty, Sepuluh Nopember Institute of Technology, \\ Surabaya, Indonesia \\ Correspondence: Nyoman Puspa Asri, Department of Chemical Engineering, W R. Supratman University, \\ Indonesia. E-mail: nyoman_puspaasri@yahoo.com
}

Received: May 4, 2015

doi:10.5539/mas.v9n7p99
Accepted: June 5, 2015

Online Published: June 30, 2015

URL: http://dx.doi.org/10.5539/mas.v9n7p99

\begin{abstract}
Synthesis of biodiesel is a strategic step in overcoming energy scarcity and the environmental degradation caused by the continuous use of the petroleum based energy. Biodiesel as an alternative fuel for diesel engine is produced from renewable resources such as vegetable oils and animal fats. The main obstacle in the biodiesel production is the high price of the raw materials, resulting in the price of biodiesel is not competitive compared to the petroleum diesel. Therefore, the use of waste frying oils (WFO) is one way to reduce the cost of biodiesel production, because of its availability and low price. In the present work, WFO from California Fried chicken (CFC) restaurants in Surabaya were used as feed stock for the biodiesel production. The experiments were conducted using three steps of processes: pre-treatment of WFO, preparation of alumina based composite catalyst $\mathrm{CaO} / \mathrm{KI} / \gamma-\mathrm{Al}_{2} \mathrm{O}_{3}$ and transesterification of treated WFO. WFO was treated by several types and various amounts of activated adsobents. The treated WFO was transesterified in three neck glass batch reactor with refluxed methanol using $\mathrm{CaO} / \mathrm{KI} / \gamma-\mathrm{Al}_{2} \mathrm{O}_{3}$. The results reveal that the best method for treating WFO is using $7.5 \%$ (wt. \% to WFO) of coconut coir. Alumina based composite catalyst $\mathrm{CaO} / \mathrm{KI} / \gamma-\mathrm{Al}_{2} \mathrm{O}_{3}$ was very promising for transesterification of WFO into biodiesel. The yield of biodiesel was $83 \%$ and obtained at $65^{\circ} \mathrm{C}, 5 \mathrm{~h}$ of reaction time, 1:18 of molar ratio WFO to methanol and 6\% amount of catalyst.
\end{abstract}

Keywords: alumina based composite catalyst, biodiesel production, pre-treatment, waste frying oils

\section{Introduction}

The depleting reserves and uncertainty price of world crude oil have motivated the researcher for developing alternative fuel, particularly for transportation and industrial fuels. Biodiesel is very potential to replace fossil fuels, because it is produced from renewable resources that its continuity can be maintained as long as biomass feedstock is available. Biodiesel is a methyl ester derived from vegetable oils, animal fats or waste cooking oil through transesterification process (Asri et al., 2013). Biodiesel offer many advantages such as non-toxic, high flash point, high cetane number, high lubricity, low volatility or flammability, good transport and storage properties, low carbon monoxide emissions and biodegradable (Asri et al., 2013; Uddin et al., 2013). Therefore, it is considered as an environmentally friendly fuel (Asri et al., 2013). Transesterification process or usually called alcoholyses is the reaction between the hydroxyl groups of alcohols and carboxylic groups of triglycerides to form esters (Asri et al., 2013). A schematic of trasesterification process are shown in Figure 1

Currently, biodiesel is produced through transesterification process using a homogeneous catalyst such as sodium hydroxide $(\mathrm{NaOH})$ or potassium hydroxide $(\mathrm{KOH})$ (Asri et al., 2013; Wong et al., 2014). However, this process has limitations such as the catalyst cannot be regenerated and reused. Recovery of the catalyst is a complicate process and requires few steps in which the product must be neutralized with an acid and washed with water to separate the catalyst from the product (Asri et al., 2013; Wong et al., 2014). This process will generate a large amount of waste water, and creates other environmental problems as well as increasing in the production cost (Asri et al., 2013).

In Indonesia, biodiesel is derived from refined edible oils, mostly palm oil. The advantage of using refined oil as the raw material for the production of biodiesel is their low free fatty acid content. However, cost of biodiesel produced from refined vegetables oil through transesterification is higher than fossil fuel diesel oil, due to the high raw material cost. 


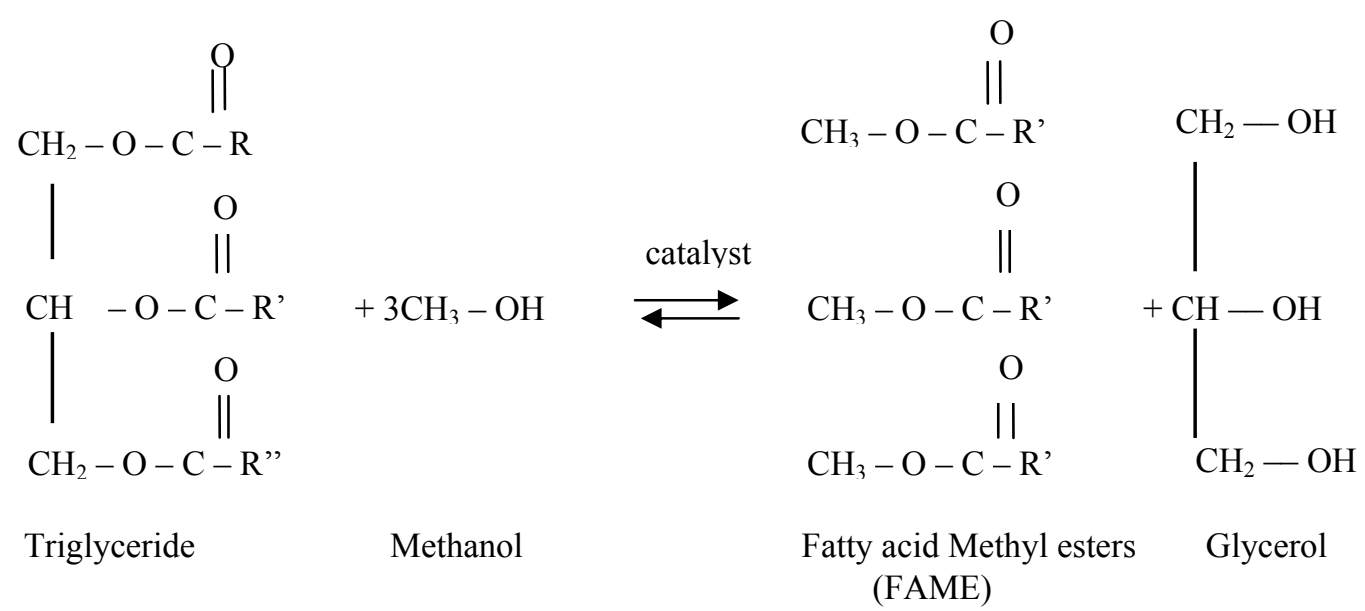

Figure 1. A schematic of trasesterification Proces

In order to minimize the production cost of biodiesel production, waste frying oil (WFO) can be used as alternative feedstock due to its availability and low cost (Canakci, 2007). Generally, in most of hotels, restaurants, and in other food industries, WFO is simply discharged into the sewer or dumped into the land. Besides offering substantial environmental benefit, it also provides an alternative solution for the final disposal of the oil (Araujo et al., 2013). Therefore, WFO can be used effectively for the biodiesel synthesis, and it is found to be an economically feasible method (Supple et al., 2002). Biodiesel from WFO can reduce the cost of biodiesel production since the feedstock costs constitutes approximately $70-95 \%$ of the overall cost of biodiesel production (Diwani et al., 2009; Lam et al., 2010; Asri et al., 2014; Alves et al., 2013). The property of biodiesel depends on the type of fresh cooking oil used.

WFO contains high free fatty acid content than the fresh one. The free fatty acid and moisture content are the key parameters for determining the viability of vegetable oils to be used in transesterification process (Gashaw and Teshita, 2014). Water content in WFO will accelerate the hydrolysis reaction and simultaneously reduce the amount of ester formation (Leung and Guo, 2006). Water content should not exceed $0.5 \%$ to obtain $90 \%$ yield of biodiesel (Gnanaprakasam et al., 2013). Moreover, it was known that higher free fatty acid contents will lead to formation of soap and water. If free fatty acid content more than $3 \%$, the homogeneous base catalyst is not suitable for the transesterification reaction (Gnanaprakasam et al., 2013).

Homogeneous base-catalyzed transesterification reaction for biodiesel production requires water free and low acid value $(<1)$ raw materials. If the oil samples have high FFA content $(>1 \%)$ then the reaction requires more alkali catalyst to neutralize the FFA (Gashaw and Teshita, 2014). To overcome these problems, the effort should be made to reduce the levels of FFA and water content in the WFO to make it suitable as the raw material for biodiesel production. To address the problem is by pre-treated of WFO before the transesterification process into biodiesel. Several types of pre-treatment processes of waste cooking oil are available such as: steam injection, neutralization, and vacuum evaporation (Araujo et al., 2013). Another references reported some other pre-treatment methods have also been in used to reduce the FFA and water content in WFO such as filtration and drying by microwave oven at $60{ }^{\circ} \mathrm{C}$ for 10 minutes, use drying agent of magnesium sulphate followed by filtration under vacuum to remove any suspended mater and magnesium crystal (Araujo et al., 2013). The use of adsorbent such as activated carbon, bleaching earth and other adsorbents is other option for the treatment of WFO. However, the most widely used method to remove FFA content from the oil is esterification process with acid as the homogeneous catalyst, this process converts FFA into free fatty acid ester.

The emergence of heterogeneous catalysts seems to be a promising solution to overcome the drawback of using the homogeneous catalyst in the biodiesel production ('Asri et al., 2013). Various heterogeneous metal oxides catalysts (Jitputti et al., 2006; Zabeti et al., 2009; Furuta et al., 2012) have been employed in the transesterification process. Many studies showed that $\mathrm{CaO}$ is a potential catalyst in transesterification process due it advantages such as: high basic strength, low solubility in methanol, non-toxic, and mild operating conditions (Zabeti et al., 2009; Kouzu et al., 2008; ${ }^{b}$ Asri et al., 2013). It is also low cost catalyst, because it can be synthesized from cheap material like lime stone and $\mathrm{Ca}(\mathrm{OH})_{2}$ (Lam et al., 2010).

The aims of this study are to reduce the FFA and water content of waste frying oil and to explore the possibility of using heterogeneous base catalyst for the transesterification of waste frying oil into biodiesel. In this work, the 
synthesized $\gamma$-alumina composite base catalyst $\mathrm{CaO} / \mathrm{KI} / \gamma-\mathrm{Al}_{2} \mathrm{O}_{3}$ were used to convert WFO into biodiesel. In order to reduce the level of free fatty acid content, waste frying oil was treated by various types of adsorbents which consist of: activated carbon, bleaching earth and coconut (Cocos nucifera L.) coir.

Other objectives of the present work are to study the effect of the types and amount of adsorbents used in the pre-treatment process of WFO to reduce the FFA content and to investigate the effect of reaction time on yield of biodiesel during the transesterification process.

\section{Method}

\subsection{Material}

The waste frying oil (WFO) as the feedstock was collected from California Fried Chicken's (CFC's) fast food restaurant. The physical and chemical characteristics of CFC's WFO were analyzed using several methods, and it consists of: $53.01 \%$ of palmitic acid and $46.99 \%$ of oleic acid. Meanwhile, FFA, density and water content of CFC's WFO were $2.82 \%, 0.92 \mathrm{~g} / \mathrm{cm}^{3}$ and $0.69 \%$, respectively. Technical grade of Activated Carbon and bleaching earth for treating WFO were supplied by local supplier Bratacho-chem. Coconut coir, another cheap adsorbent was obtained from local coconut processing mill in Lamongan city, East Java Province. Analytical grade of $\gamma$--alumina was used as catalyst support, while $\mathrm{KI}$ and $\mathrm{CaO}$ as promotor were purchased from Merck, Germany. Meanwhile, $\mathrm{NaOH}$, methanol, and acetic acid were purchased from local supplier Bratacho-chem.

\subsection{Preparation of Adsorbent}

Activated carbon and bleaching earth that has been purchased from a local supplier can be directly used without any treatment. However, it needs special preparation for coconut coir before being used as an adsorbent. At first, coconut coir soaked and washed with water several times to remove the brown color. It was cut into small pieces and crushed in the crushing unit until it becomes a powder. Afterwards, the coconut coir powder will be dried in an oven at $105-110^{\circ} \mathrm{C}$ for one night. It was sieved using a 60 mesh sieve to obtain particle in this range. The dry powdered of coconut coir was stored in the plastic bag before used for treating WFO. It was ready for treating WFO, without chemical and physical treatment anymore prior the adsorption process.

\subsection{Pre-treatment of Waste Frying Oil (WFO)}

The pre-treatment of waste frying oil was conducted by adsorption process. The adsorption process was carried out by several types of adsorbents such as technical grade activated carbon, bleaching earth, coconut coir powdered, mixture of activated carbon and bleaching earth, and a mixture of activated carbon and coconut coir powdered. In the first step of the processes, WFO was filtered to eliminate food residues or suspended solid matter, then heated at $100-105{ }^{\circ} \mathrm{C}$ for 30 minutes to remove water content. Subsequently, the same amount of filtered and heated WFO was placed into a series of beaker glasses. Several types and various amounts of adsorbents (wt. \% to oil) were added into beaker glass. There were 7 series of adsorption experiments which consist of: 1 experiment without treatment (WA), 3 experiments with various amounts of activated carbon (AC) $(5,10$ and $15 \%), 1$ experiment with mixture of $10 \% \mathrm{AC}$ and $10 \%$ of bleaching earth (BE), 1 experiment with mixture of $10 \%$ of $\mathrm{AC}$ and $5 \%$ of coconut coir (CC), and 1 experiment with $7.5 \% \mathrm{CC}$. Each beaker glass was heated at $100^{\circ} \mathrm{C}$ while stirring at a constant speed of $60 \mathrm{rpm}$ for $1 \mathrm{~h}$. After the adsorption process completed, the mixture was filtered to separate the adsorbent from the solution. Then the treated WCOs were analyzed to determine the FFA content, water content and the density.

\subsection{Catalyst Preparation}

Catalyst used in this study was $\gamma$-alumina supported catalyst $\mathrm{CaO} / \mathrm{KI} / \gamma-\mathrm{Al}_{2} \mathrm{O}_{3}$. Catalyst was synthesized by precipitation and impregnation method. Calcium acetate with $30 \% \mathrm{CaO}$ loading (wt. \% to the $\gamma-\mathrm{Al}_{2} \mathrm{O}_{3}$ support) was synthesized stoichiometricaly from $\mathrm{CaO}$ and acetic acid. Afterward, $\gamma$-alumina was poured into the calcium acetate solution and stirred for 3-4 $\mathrm{h}$ at room temperature. The formed suspension was impregnated by $35 \%$ of KI solution with $30 \%$ of KI loading (wt. \% to Al2O3). The mixture was heated and stirred at $80^{\circ} \mathrm{C}$ or $3 \mathrm{~h}$. The obtained slurry was dried in an oven at 105-110 $\mathrm{C}$ for 12 hours. The yellowish white crystals crushed to a fine powder, calcinated at $650 \mathrm{C}$ in muffle furnace unit for $5 \mathrm{~h}$. The procedure of $\mathrm{CaO} / \mathrm{KI} / \gamma-\mathrm{Al}_{2} \mathrm{O}_{3}$ preparation has been described in the previous work ( ${ }^{\mathrm{b}}$ Asri et al., 2013).

The synthesized $\mathrm{CaO} / \mathrm{KI} / \gamma-\mathrm{Al}_{2} \mathrm{O}_{3}$ catalyst was characterized by mean of X-Ray Diffraction (XRD), Brunauer-Emmett-Teller (BET) and Scanning Electron Microscope (SEM) analysis. XRD gives information on the crystallization structure. BET method was used for measuring the specific surface area, pore volume and pore diameter of the prepared catalysts. Meanwhile, to identify the morphology and size of $\mathrm{CaO} / \mathrm{KI} / \gamma-\mathrm{Al}_{2} \mathrm{O}_{3}$ catalyst particle the SEM method was used (Jeol, JSM-6390LV, Japan). 


\subsection{Transesterification Reaction}

The activity of the prepared catalyst $\left(\mathrm{CaO} / \mathrm{KI} / \gamma-\mathrm{Al}_{2} \mathrm{O}_{3}\right)$ was tested by transesterification of treated waste frying oil and methanol in a batch-type reactor. After treating, WFO was eventually transesterified in three neck glass batch type reactor with refluxed methanol using $\mathrm{CaO} / \mathrm{KI} / \gamma-\mathrm{Al}_{2} \mathrm{O}_{3}$ catalyst. The experiments were conducted at various reaction time 1 to 7 hours with one hr of range, other conditions such as reaction temperature of $65^{\circ} \mathrm{C}$, amount of catalyst of $6 \%$ (wt. \% to oil), and molar ratio of WFO to methanol of 1:18 were kept constant.

About $46 \mathrm{~g}$ of treated WFO, $31.20 \mathrm{~g}$ of methanol (molar ratio WFO to methanol 1:18) and $2.76 \mathrm{~g}(6 \% \mathrm{w} / \mathrm{w}$ to WFO) of catalyst were mixed in a $250 \mathrm{~mL}$ three-necked flask equipped with reflux condenser and magnetic hot plate stirrer. The mixture was heated at $65^{\circ} \mathrm{C}$ in water bath while stirring in a constant speed for $5 \mathrm{~h}$. The collected reaction mixture was then centrifuged at $3000 \mathrm{rpm}$ for 5-10 min to separate catalyst, glycerol and methyl esters phases. The glycerol and methyl esters phases were loaded into a rotary evaporator to recover the excess methanol in mixture. The mixture was then poured into the separating funnel to separate glycerol and methyl ester phase. Biodiesel concentration was analyzed by a gas chromatograph GC-14B (model Shimadzu) equipped with a flame ionization detector and a capillary column HP-Innowax $(30 \mathrm{~m} \times$ id $0.25 \mathrm{~mm}, 0.25 \mu \mathrm{m})$. Helium was used as the carrier gas throughout the whole experiment. Biodiesel analyses can be used to determine the yield \% of biodiesel defined as follows ( ${ }^{\mathrm{b}}$ Asri et al., 2013):

$$
\text { Yield of biodiesl }(\%)=\frac{w_{\text {of actual bioiesel }}}{w_{\text {of oil }}} \times 100 \%
$$

where, $w$ of actual biodiesel was calculated from weight of biodiesel produced (mg) in the experiment multiple by weight $\%$ of FAME in the sample. Meanwhile, $W_{\text {of oil }}$ is weight of oil $(\mathrm{mg})$ used in the experiment.

\section{Results and Discussion}

\subsection{Effect of the Types and amount of Adsorbents on FFA Content of WFO}

In order to reduce the FFA and water content of WFO, it was treated by several types of adsorbent which consist of: various amount of technical grade activated carbon (AC) $(2,5,10$ and $15 \%)$, coconut coir (CC) $7.5 \%$, a mixture both of them (10\% of AC and $5 \%$ of $\mathrm{CC})$, a mixture of $\mathrm{AC}$ and bleaching earth (BE) $(10 \%$ of $\mathrm{AC}$ and $10 \%$ of $\mathrm{BE}$ ). Theoretically, the activities of type and amount of adsorbent (wt. \% to the WFO) could be correlated to the FFA content of WFO.

Figure 2 shows the influence of type and amount of adsorbent to FFA content of Waste frying oil. It seen, that type and amount of adsorbent influenced significantly to the FFA content of WFO. Without treatment, the initial FFA content of WFO was $2.82 \%$. Treatment with $2 \%$ amount of AC can significantly reduce the FFA content to $1.52 \%$. It means, the percentage removal of the FFA content is about $46 \%$ to the initial FFA content of WFO. However, with the increase amount AC loading up to $10 \%$, FFA content decreased to $1.19 \%$, which mean the removal of FFA content is $66 \%$. The percentage of FFA removal increased with an increase in amount of adsorbent. Etim et al. (2012) stated, that the increase in adsorption capacity with amount of adsorbent can be associated to an increase in the adsorption surface and availability of adsorption sites. In contrary, the $15 \%$ increasing amount of AC, FFA content increased into $1.21 \%$. That happens because the solution is too viscous, resulting inhibits the absorption process. As well as using a mixture of $10 \%$ of $\mathrm{AC}$ and $10 \%$ of $\mathrm{BE}$, there is no a significant effect to the reducing of FFA content.

In this work, $7.5 \%$ of $\mathrm{CC}$ and a mixture of $10 \% \mathrm{AC}$ and $5 \% \mathrm{CC}$ also introduced as an adsorbent to reduce the FFA content of WFO. A mixture of $10 \% \mathrm{AC}$ and $5 \%$ of CC can significantly reduce the FFA content into $0.80 \%$. Meanwhile, with $7.5 \%$ of CC powdered the FFA content WFO was drastically decreased into $0.31 \%$. Therefore, in this work has found that $7.5 \%$ of CC powdered was the optimum condition. Absorptive capability of coconut coir was better than that of activated carbon or bleaching earth. This is possible because the porosities of coconut coir are relatively higher than that of the activated carbon or bleaching earth, and it will lead the decreasing of FFA level of WCO. It was reported that coconut coir to be composed of cellulose, pentosan, furfural and lignin (Etim et al., 2012). Hence, $7.5 \%$ of CC powdered was selected to be used for treating WFO in the further studies. The use of coconut coir for pretreatment of WFO, besides bringing a great benefit to the environment, it also very cheap, and sustained availability as agricultural waste.

Other properties that were analyzed are density and water content. Before treatment, the density and water content of WFO are $0.92 \mathrm{~g} / \mathrm{cm}^{3}$ and $0.69 \%$. After treatment, the density and water content decrease to $0.91 \mathrm{~g} / \mathrm{cm}^{3}$ and $0.03 \%$, for all series of treatment. It was indicated, that there weren't a significant effect of treatment on the density of WFO. However, treatments by various type and amount of adsorbent give the same result and a significant effect on the water content of WFO. 


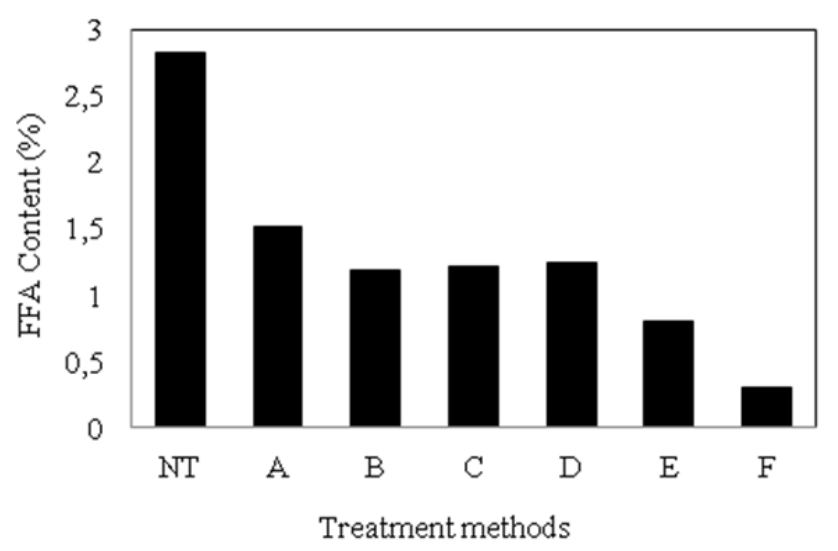

Figure 2. Effect of the types and amount of adsorbents on FFA content of WFO. NT= no treatment, $A=$ treatment with $2 \%$ of activated carbon, $\mathrm{B}=$ treatment with $10 \%$ of activated carbon, $\mathrm{C}=$ treatment with $15 \%$ of activated carbon, $\mathrm{D}=$ treatment with $10 \%$ activated carbon $+10 \%$ bleaching earth, $\mathrm{E}=$ treatment with $10 \%$ of activated carbon $+5 \%$ of coconut coir powdered, $\mathrm{F}=$ treatment with $7.5 \%$ of coconut coir powdered

\subsection{Characterization of Catalyst}

$\mathrm{X}$-ray diffraction gives the information of transformation structure on crystallization. X-RD pattern of $\mathrm{CaO} / \mathrm{KI} / \gamma-\mathrm{Al}_{2} \mathrm{O}_{3}$ is given in Figure 2. It seen that the characteristic peaks of alumina at $2 \theta$ of 37.0, 46.0, and 66.7 ${ }^{\circ}$ were still exist and almost unchanged in the X-RD pattern (Xie and Li, 2006; Asri et al., 2013). It's indicates that alumina still retained its amorphous structure. The characteristic peaks of $\mathrm{CaO}$ were found at $2 \theta$ of 34,54 and $65^{\circ}$. The characteristic peaks of $\mathrm{K}_{2} \mathrm{O}$ were obtained at $2 \theta$ of 31,41 and $57^{\circ}$. Meanwhile, the characteristic peaks of $\mathrm{KI}$ much more than the others. It means that $\mathrm{CaO}$ and $\mathrm{KI}$ partly dispersed on porous surface of alumina. Part of them was retained on surface of catalyst as sites active. Part of KI that was remained on the surface of catalyst were easily decomposed into $\mathrm{K}_{2} \mathrm{O}$ and $\mathrm{I}_{2}$, Therefore, at the surface of catalyst there were several characteristic peaks of crystalline $\mathrm{CaO}, \mathrm{K}_{2} \mathrm{O}$ and $\mathrm{KI}$, which enhance the activity of catalyst. Moreover, the emergence of those crystalline, could increase the basicity of catalyst, which resulting the increase of catalyst activity (Xie and Li, 2006; bAsri et al., 2013). In transesterification reaction, basicity was also an important factor aside from surface area.

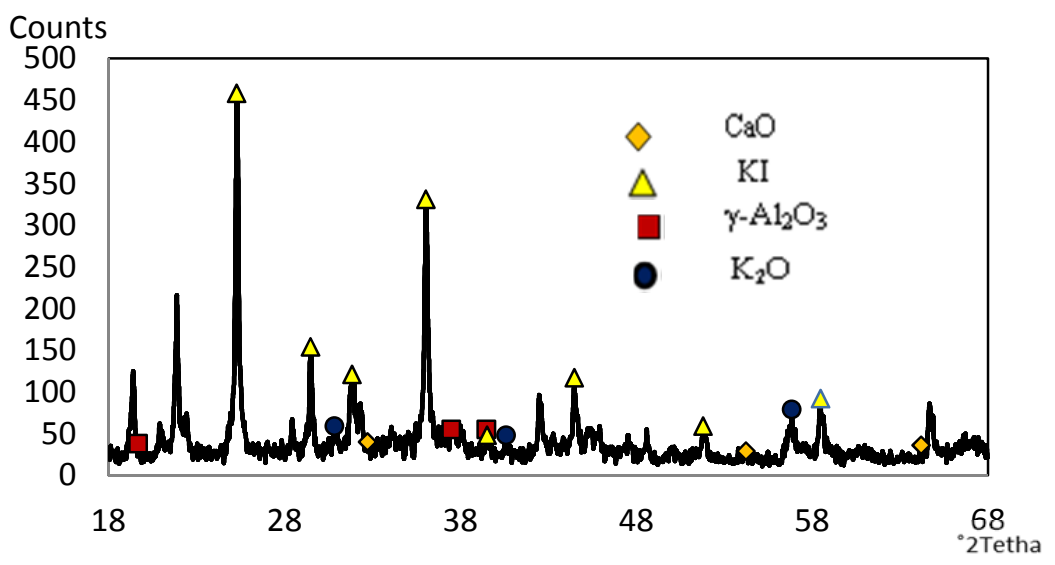

Figure 3. XR-D Pattern of $\mathrm{CaO} / \mathrm{KI} / \gamma-\mathrm{Al}_{2} \mathrm{O}_{3}$ catalyst

The specific surface area, pore volume and pore diameter of the prepared catalysts were measured using the Brunauer-Emmett-Teller (BET). The specific surface area, pore volume and pore diameter of $\mathrm{CaO} / \mathrm{KI} / \gamma-\mathrm{Al}_{2} \mathrm{O}_{3}$ were $17.24 \mathrm{~g} / \mathrm{m}^{2}, 6.39 \mathrm{E}-2 \mathrm{cc} / \mathrm{g}$ and $1.48 \mathrm{E}+01 \mathrm{~nm}\left(148^{\circ} \mathrm{A}\right)$, respectively. The specific surface area of prepared was smaller than that $\gamma-\mathrm{Al}_{2} \mathrm{O}_{3}$ (surface area of $\gamma-\mathrm{Al}_{2} \mathrm{O}_{3}$ was $120-190 \mathrm{~g} / \mathrm{m}^{2}$ ), this might due to the alkaline compound of $\mathrm{CaO}, \mathrm{K}_{2} \mathrm{O}$ and $\mathrm{KI}$ covered partly the porous surface area of $\gamma-\mathrm{Al}_{2} \mathrm{O}_{3}$. This result also smaller than that of single promoted catalyst $\mathrm{CaO} / \gamma-\mathrm{Al}_{2} \mathrm{O}_{3}$ that synthesized by by Zabeti et al. (2010) and Asri et al.(2010), which the surface area each of them were 82.74 and $83.77 \mathrm{~g} / \mathrm{m}^{2}$. As confirmed by X-ray diffraction that partly of the porous surface area of catalyst was covered by crystalline of $\mathrm{CaO}, \mathrm{K} 2 \mathrm{O}$ and $\mathrm{KI}$. However, the existence of the 
new crystalline phases, which could be increased the basic strength and basicity of the catalyst.

Meanwhile, the SEM images of $\mathrm{CaO} / \mathrm{KI} / \gamma-\mathrm{Al}_{2} \mathrm{O}_{3}$ with $30 \%$ of $\mathrm{CaO}$ loaded, has been well described in the previous work, the figure was not shown in this work (Asri et al., 2013). It was reported, that the SEM image shows crystallites of $10 \mu \mathrm{m}$ in size with nearly to irregular coral shapes. It was also stated that the prepared catalyst was a mesoporous structure.

\subsection{Effect of Reaction Time on Yield of Biodiesel in Transesterification of WFO}

To evaluate the activity of the prepared catalyst $\mathrm{CaO} / \mathrm{KI} / \gamma-\mathrm{Al}_{2} \mathrm{O}_{3}$ on the transesterification of the treated WFO, the experiments were conducted by varying time of reaction from 1 to $7 \mathrm{~h}$ with range of $1 \mathrm{~h}$. Meanwhile, the others conditions were kept constant, at $65^{\circ} \mathrm{C}$, molar ratio treated WFO to methanol of $1: 18$, and amount of catalyst of $6 \%$ (wt. \% to WFO). Figure 4 indicate that yield of biodiesel significanly increases by increasing of the time of reaction. In the $1 \mathrm{~h}$ of reaction, yield of biodiesel was low, because it is a heterogeneous reaction and the mass trasnsfer is low. The similar thing was reported by Huaping et al.(2006). After 1 up to $4 \mathrm{~h}$, yield of biodiesel increase rapidely up to $77.45 \%$. At reaction time of 4 up to $5 \mathrm{~h}$, biodiesel yields were gradually increased from 77.45 to $83.2 \%$. The equilibrium condition was achieved at $5 \mathrm{~h}$ with highest yield of $83.2 \%$. Meanwhile, beyond the reaction time of $5 \mathrm{~h}$, the excess of exposure of the reaction time had no significant effect to the yield of biodiesel. It can be stated that the yield of biodiesel increased up to a certain time of reaction. The similar thing stated by Refaat et al. (2008) and Asri et al. (2013).

Hence, for the economical point of view, reaction time should be optimized to reduce the production cost of biodiesel. Therefore, in this work, the reaction time of $5 \mathrm{~h}$ was stated as the optimum of reaction time to transesterification of waste frying oil into biodiesel, with high conversion of $83.2 \%$ was achieved.

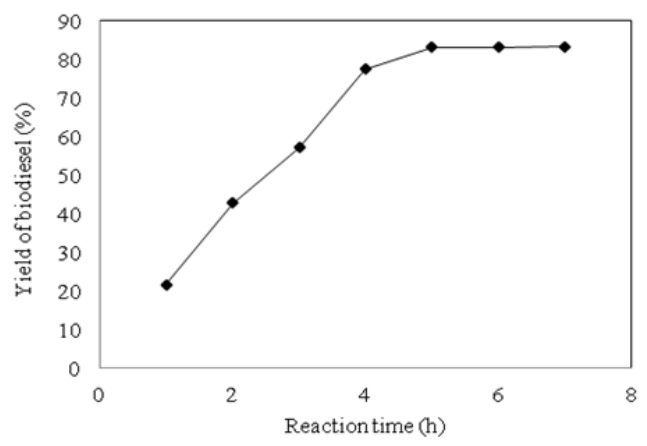

Figure 4. Effect reaction time on yield of biodiesel, at $65^{\circ} \mathrm{C}$, molar ratio WFO to methanol of $1: 18$ and amount of catalyst of $6 \%$ (wt. $\%$ to WFO)

\section{Conclusion}

Biodiesel was prepared from waste frying oil that was collected from fast food restaurant of California fried chicken (CFC). High fatty acid content of waste frying oil could be reduced by pre-treating waste frying oil with some types of adsorbent. In this work, $7.5 \%$ of coconut coir was founded the best one for reducing the FFA content of waste frying oil compare to the others (activated carbon, bleaching earth or a mixture two of them). The treated waste frying oil is very promising to be transesterified into biodiesel using $\gamma$-alumina supported composite catalyst $\mathrm{CaO} / \mathrm{KI} / \gamma-\mathrm{Al}_{2} \mathrm{O}_{3}$. High biodiesel yield of $83.2 \%$ was obtained at $65^{\circ} \mathrm{C}, 5 \mathrm{~h}$ of reaction time, $1: 18$ of molar ratio WFO to methanol and $6 \%$ amount of catalyst.

\section{Acknowledgments}

The research was supported by directorate of research and community services, Directorate General of higher education, Education and culture Ministry of the Republic Indonesia, as contained in the memorandum of agreement No: 011/SP2H/P/K7/KM/2014.

\section{References}

Asri, N. P., Machmudah, S, Wahyudiono, W., Suprapto, S., Budikarjono K., Roesyadi, A., \& Goto, M. (2013a). Non Catalytic Transesterification of Vegetables Oil to Biodiesel in Sub-and Supercritical Methanol: A kinetic's study. Bulletin of Chemical Reaction Engineering \& Catalysis, 7(3), 215-223. http://dx.doi.org/10.9767/bcrec.7.3.4060.215-223

Alves, C. T., Oliveira, A., Carneiro, S. A. V., Silva, A. G., Andrade, H. M. C., Vieira de Melo, S. A. B., Torres, 
E. A. (2013). Transesterification of waste frying oil using a zinc aluminate catalyst. Fuel Processing Technology, 106, 102-107. http://dx.doi.org/10.1016/j.fuproc.2012.07.008

Araujo, C. D. M., Andrade, C. C, Silva, E. S., \& Dupas, F. A. (2013). Biodiesel production from used cooking oil: A review. Renewable and Sustainable Energy Reviews, 27, 445-452. http://dx.doi.org/10.1016/j. rser.2013.06.014

Asri, N. P., Machmudah, S., Wahyudiono, W., Suprapto, S., Budikarjono, K., Roesyadi, A., \& Goto, M. (2013b). Palm oil transesterification in sub and supercritical methanol with heterogeneous base catalyst. Chemical Engineering and Processing: Process Intensification, 72, 63-67. http://dx.doi.org/10.1016/j.cep.2013. 07.003

Canakci, M. (2007). The potential of restaurant waste lipids as biodiesel feedstocks. Bioresource Technology, 98(1), 183-190.

Diwani, G. E., Attia, N. K., \& Hawash, S. I. (2009). Development and evaluation of biodiesel fuel and by-products from jatropha oil. International Journal of Environmental Science and Technology, 6(2), 219-224.

Etim, U. J., Umoren, S. A., \& Ednok, U. M. (2012). Coconut coir dust as a low adsorbent for the removal of cationic dye from aqueous solution. Journal of Saudi Chemical Society (Article in Press). http://dx.doi.org/10.1016/Jjscs.2012.09.014

Furuta, S., Matsuhashi, H., \& Rata, K. (2006). Biodiesel diesel fuel production with solid amorphous-zirconia catalyst in fixed bed reactor. J. Biomass and Bioenergy, 30, 870-873. http://dx.doi.org/10.1016/j.biombioe.2005.10.010

Gashaw, A., \& Teshita, A. (2014). Production of biodiesel from waste cooking oil and factors affecting its formation: A review. International Journal of Renewable and Sustainable Energy, 3(5), 92-98. http://dx.doi.org/10.11648/j.jirse.20140305.12

Gnanaprakasam, A., Sivakumar, V. M., Surendhar, A., Thirumarimurugan, M., \& Kannadasan, T. (2013). Recent strategy of biodiesel production from waste cooking oil and process influencing parameters: A review. Hindawi Publishing Corporation Journal of Energy, 2013, 10. http://dx.doi.org/10.1155/2013/926

Huaping, Z., Zongbin, W., Duan Shjie, C. Y., Yuangxiong, C., Ping, Z., Zongqiang, M., \& Xiaohua, L., \& Zongqiang, M. (2006). Preparation of biodiesel catalyzed by solid super base of calcium oxide and its refining process", Chinese Journal of Catalyses, 27(5), 391-396.

Jitputti, J., Kitiyanan, B., Rangsunvigit, P., Bunyakiat, K., Attnatho, L., \& Jenvanipanjakul, P. (2006). Transesterification of kernel oil and crude coconut oil by different solid catalysts. Chemical Engineering Journal, 116, 61-66.

Kouzu, M., Kasuno, T., Tajika, M., Sugimoto, Y., Yamanaka, S., \& Hidaka, J. (2008). Calcium oxide as a solid base catalyst for transesterification of soybean oil and it's application to biodiesel production. Fuel, 87 , 2798-806. http://dx.doi.org/10.1016/j.fuel.2007.10.019

Lam, M. K., Lee, K. T., \& Mohamed, A. R. (2010). Homogeneous, Heterogeneous and enzymatic catalysis for transesterification of high free fatty acid oil (waste cooking oil) to biodiesel: A review. Biotechnology advances, 28, 500-518. http://dx.doi.org/10.1016/j.biotechadv.2010.03.002

Leung, D. Y. C., \& Guo, Y. (2006). Transesterification of neat and used frying oil: Optimization for biodiesel production. Fuel ProcessingTechnology, 87(10), 883-890. http://dx.doi.org/10.1016/j.fuproc.2006.06.003

Refaat, A. A., Attia, N. K., Sibak, H. A., El Sheltawy, S. T., \& El Diwani, I. (2008). Production optimization and quality assessment of biodiesel from waste vegetable oil. International Journal of Environmental Science and Technology, 5(1), 75-82. http://dx.doi.org/10.1007/BF03325999

Supple, B., Howard-Hildige, R., Gonzalez-Gomez, E., \& Leahy, J. J. (2002). The effect of steam treating waste cooking oil on the yield of methyl ester. Journal of the American Oil Chemists 'Society, 79(2), 175-178.

Uddin, M. R., Kaniz Ferdous, Rahim Uddin, M., Khan1Maksudur, R., \& Islam, M. A. (2013). Synthesis of Biodiesel from Waste Cooking Oil. Chemical Engineering and Science, 1(2), 22-26. http://dx.doi.org/10.12691/ces-1-2-2

Wong, Y. C., Tan, Y. P., Taufik-Yap, Y. H., \& Ramli, I. (2014). Effect of calcination temperatures of CaO/Nb2O5 mixed oxides catalysts on biodiesel production. Sains Malaysiana, 43(5), 783-790. 
Xie, W., \& Haitao, Li. (2006). Alumina supported potassium iodide as a heterogeneous catalyst for biodisel production from soybean oil, $J$ Molecular Catalysis A: Chemical, 255, 1-9. http://dx.doi.org/10.1016/j.molecata.2006.03.061

Zabeti, M., Daud, W. H. A. M., \& Aroua, M. K. (2009). Activity of solid catalysts for biodiesel production: A review. Fuel Processing Technology, 90, 770-777. http://dx.doi.org/10.1016/j.fuproc.2009.03.010

Zabeti, M., Daud, W. H. A. W., \& Aroua, M. K. (2010). Biodiesel production using alumina supported cacium oxide: An optimization study, Fuel Processing Technology, 91, 243-248. http://dx.doi.org/10.1016/j.fuproc.2009.10.004

\section{Copyrights}

Copyright for this article is retained by the author(s), with first publication rights granted to the journal.

This is an open-access article distributed under the terms and conditions of the Creative Commons Attribution license (http://creativecommons.org/licenses/by/3.0/). 